\title{
Quantifying fugitive gas emissions from an oil sands tailings pond with open-path Fourier transform infrared measurements
}

Yuan You et al.

Correspondence to: Ralf M. Staebler (ralf.staebler@canada.ca)

The copyright of individual parts of the supplement might differ from the CC BY 4.0 License. 


\section{S1. Methane mole fractions, vertical profiles, and gradient fluxes}

\section{S1.1 Calibration of retrieved $\mathrm{CH}_{4}$ mole fraction from OP-FTIR}

The amplitude of spectra for all the three paths varied substantially over the study period, especially for the top path. As a proxy for the spectral amplitude, the signal-to-noise ratio (SNR) of the $\mathrm{CH}_{4}$ fitting was used. The $\mathrm{CH}_{4}, \mathrm{NH}_{3}$, $\mathrm{CH}_{3} \mathrm{OH}$ and $\mathrm{HCHO}$ mole fraction for all three paths when this SNR dropped fast, or stayed below 10 were flagged. $3 \%$ and $13 \%$ of the measurements from bottom and top path were flagged and invalidated from further mole fraction gradient and flux calculations.

Since $\mathrm{CH}_{4}$ mole fraction was also continuously measured by cavity ring-down spectroscopy (CRDS) at four heights during the study, the measurements at $4 \mathrm{~m}$ were compared to $\mathrm{CH}_{4}$ mole fraction retrieved from the FTIR bottom path to calibrate the retrieved $\mathrm{CH}_{4}$ mole fraction from three paths of this OP-FTIR system.

Each CRDS in this study was calibrated before and after the campaign, and $\mathrm{CH}_{4}$ mole fraction from three CRDS at the same height was well compared $\left(r^{2}>0.96\right.$, slope $=0.98-1.01$, intercept $\left.=0.01-0.02 \mathrm{ppm}\right)$. Therefore, $\mathrm{CH}_{4}$ mole fraction retrieved from FTIR all three paths were calibrated by the linear relationship in Fig. S1:

$\left[\mathrm{CH}_{4}\right]$ FTIR_calibrated $=1.2015 \times\left[\mathrm{CH}_{4}\right]$ FTIR_retrieved -0.397

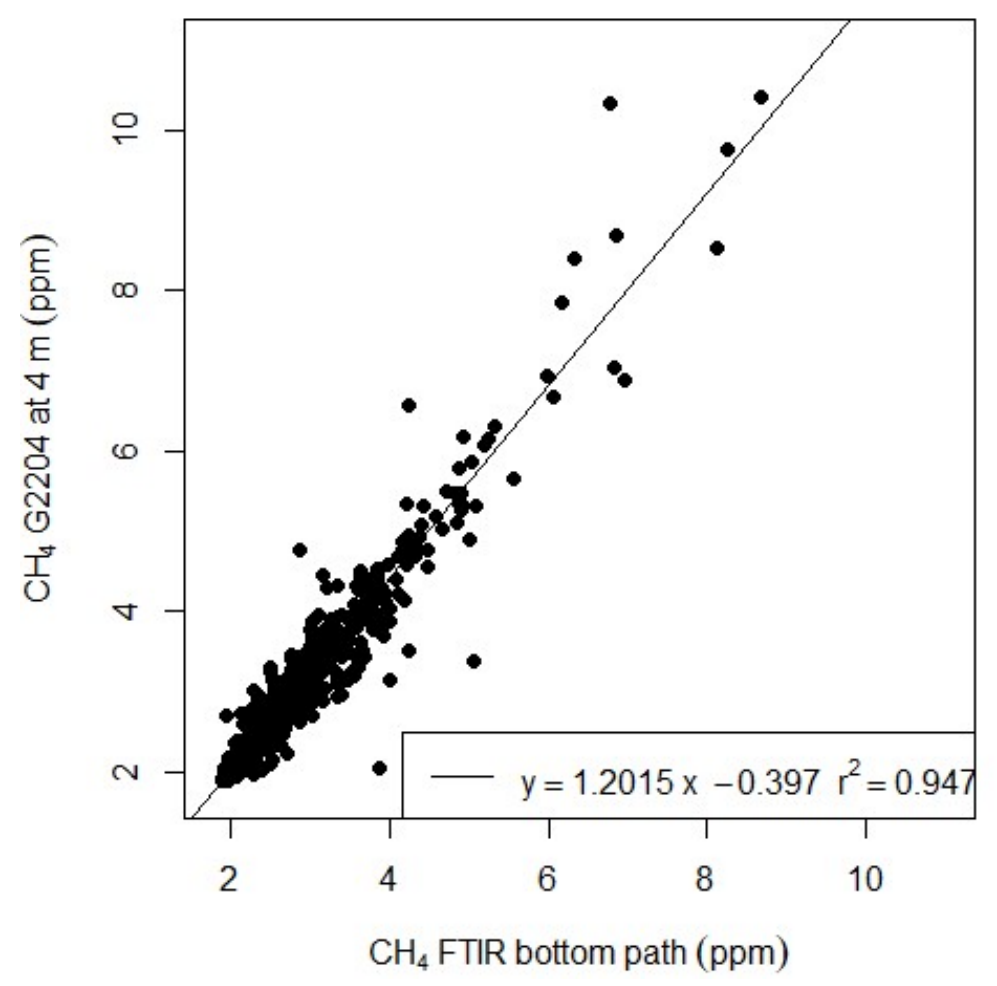

Figure $\mathrm{S} 1 \mathrm{CH}_{4}$ mole fraction retrieved from FTIR bottom path compared to $\mathrm{CH}_{4}$ mole fraction measured by CRDS (G2204) at 4m. Data are half-hour averaged results. 
S1.2 Mole fractions and vertical profiles with gradient fluxes

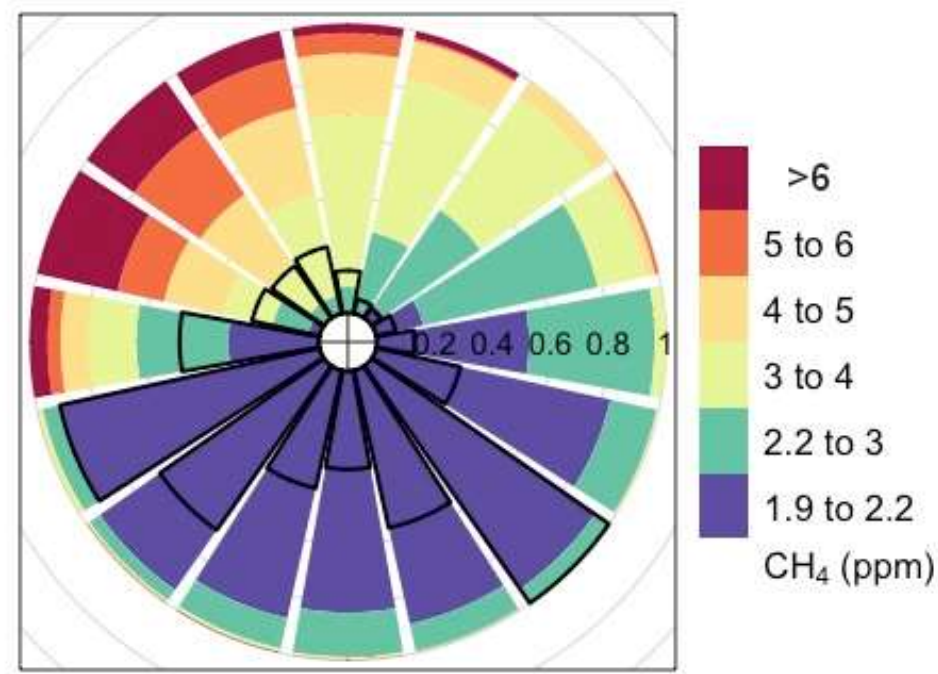

Figure $\mathrm{S} 2$ Normalised rose plot of $\mathrm{CH}_{4}$ mole fractions from FTIR bottom path. Colors represent $\mathrm{CH}_{4} \mathrm{~mole}_{\text {fractions. The }}$ length of each colored segment presents the time fractions of that mole fraction in each direction bin. The radius of the black open sectors indicates the frequency of wind in each direction bin; angle represents wind direction: straight up is north and straight left is west.

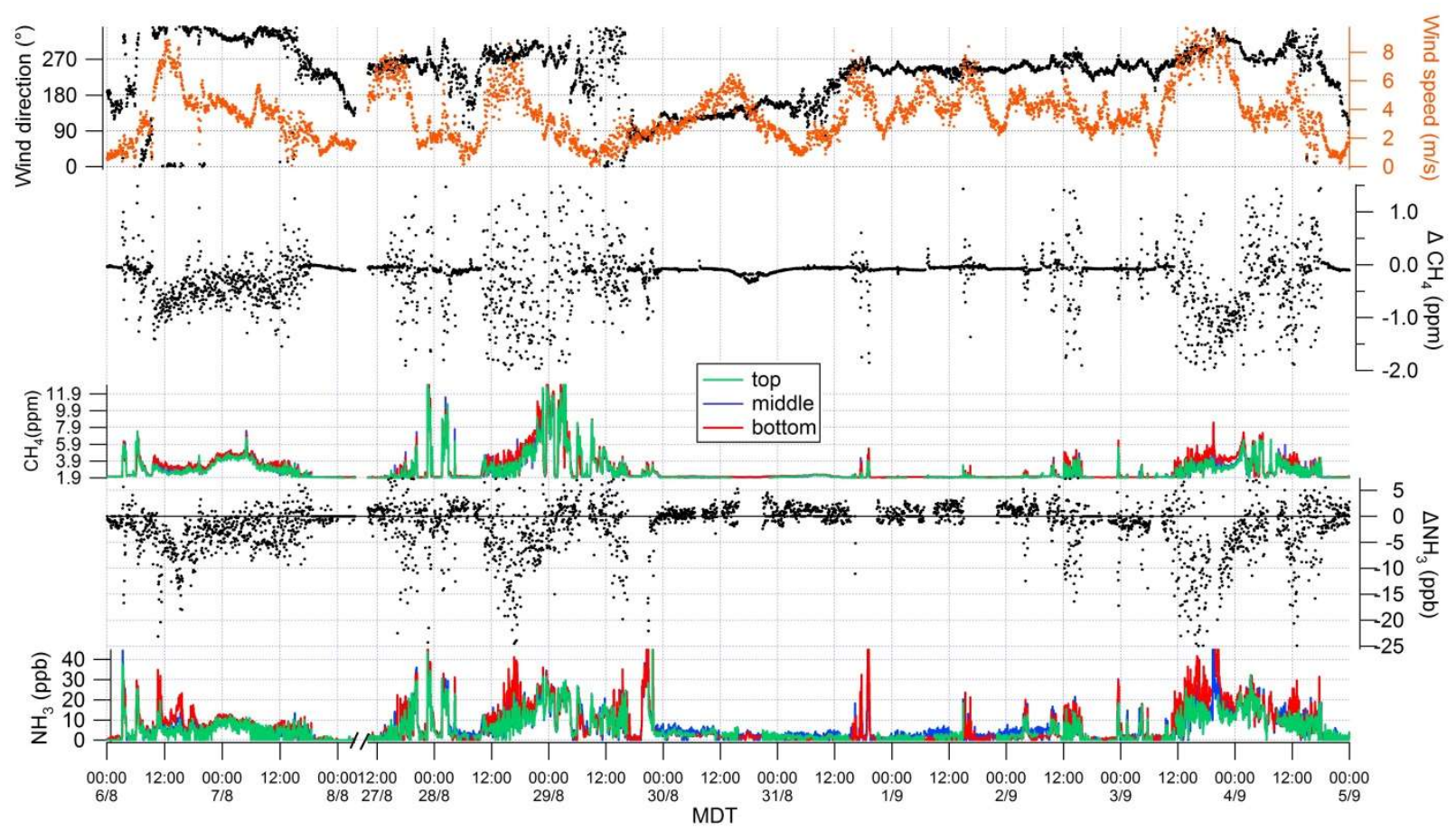

Figure $\mathrm{S} 3$ Time series of wind direction, wind speed, difference in $\mathrm{CH}_{4}$ mole fractions from the top and bottom paths, $\mathrm{CH}_{4}$ mole fractions, difference in $\mathrm{NH}_{3}$ mole fractions from the top and bottom paths, and $\mathrm{NH}_{3}$ mole fractions, from Aug $6^{\text {th }}$ to $8^{\text {th }}$, and from Aug $27^{\text {th }}$ to Sept $5^{\text {th }}$. MDT $=$ mountain daylight savings time. 
In the analysis of methane vertical profile below, all the mole fractions measurements (half-hour averages) were taken from the Picarro G2204 at 4, 8, 18, and 32m. There are 271 half-hours in total when the wind was from the pond. About $83 \%$ of the half-hour periods when the wind was from the pond direction, the $\mathrm{CH}_{4}$ vertical profiles are similar to Fig. S4. Within this $83 \%$ of periods, some profiles are close to linear, and others are not strict decreasing trend with height. For the rest of $17 \%$ of half-hour periods, the $\mathrm{CH}_{4}$ vertical profiles are closer to logarithmic (Fig. S5). Therefore, $\mathrm{CH}_{4}$ vertical profiles are considered linear over the entire period for calculating gradient flux with OP-FTIR measurement.

In addition, those half-hour periods when logarithmic relationship is better than linear to describe the vertical profile are mainly (65\%) associated with wind speed greater than $6 \mathrm{~m} \mathrm{~s}^{-1}$ (Fig. S6). For the majority of the time (85\%) when the wind was from the pond, wind speed was less than $6 \mathrm{~m} \mathrm{~s}^{-1}$ (Fig. S6).
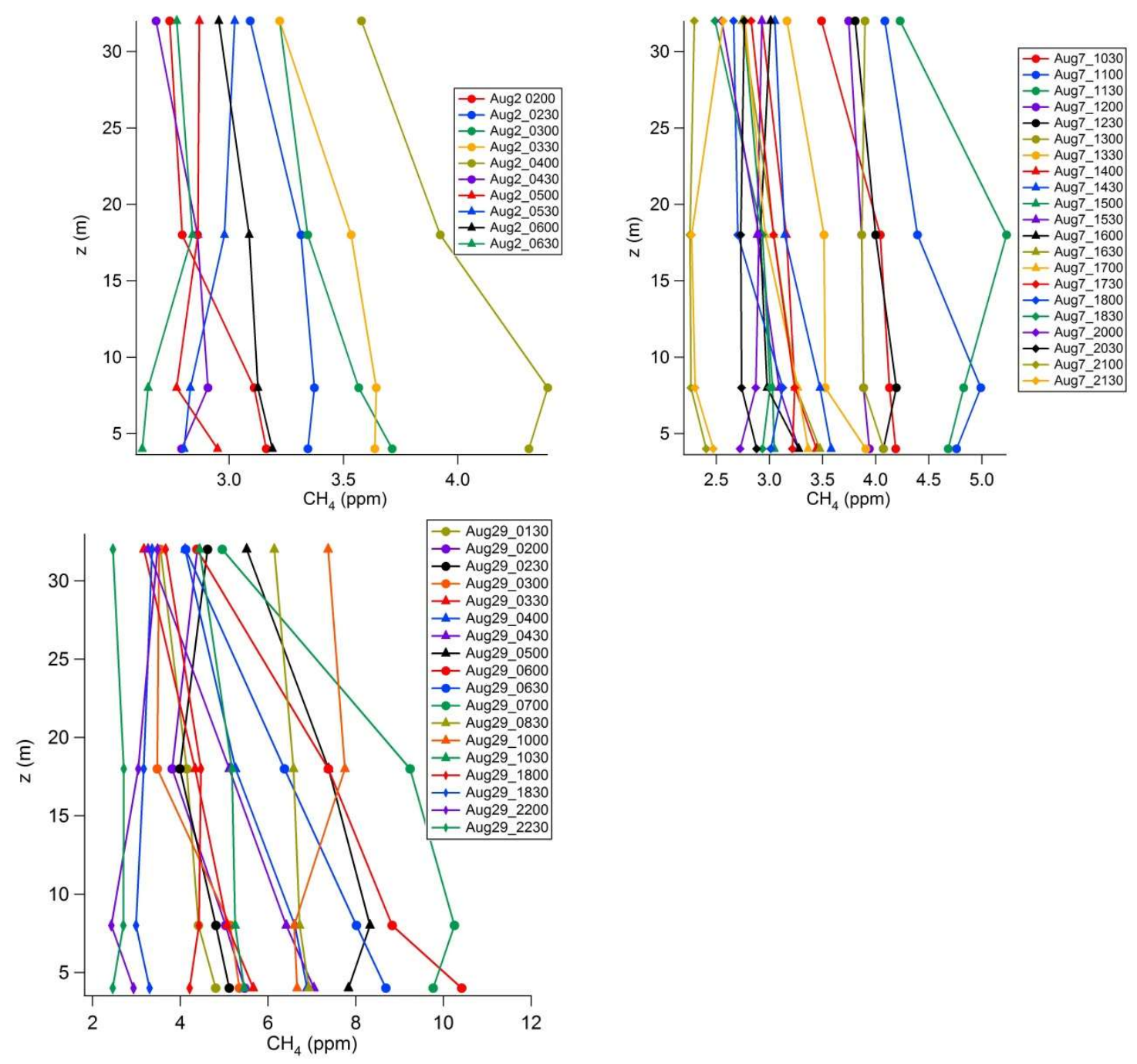

Figure S 4 Examples of observed $\mathrm{CH}_{4}$ mole fraction vertical profiles, when the profiles are close to linear. 

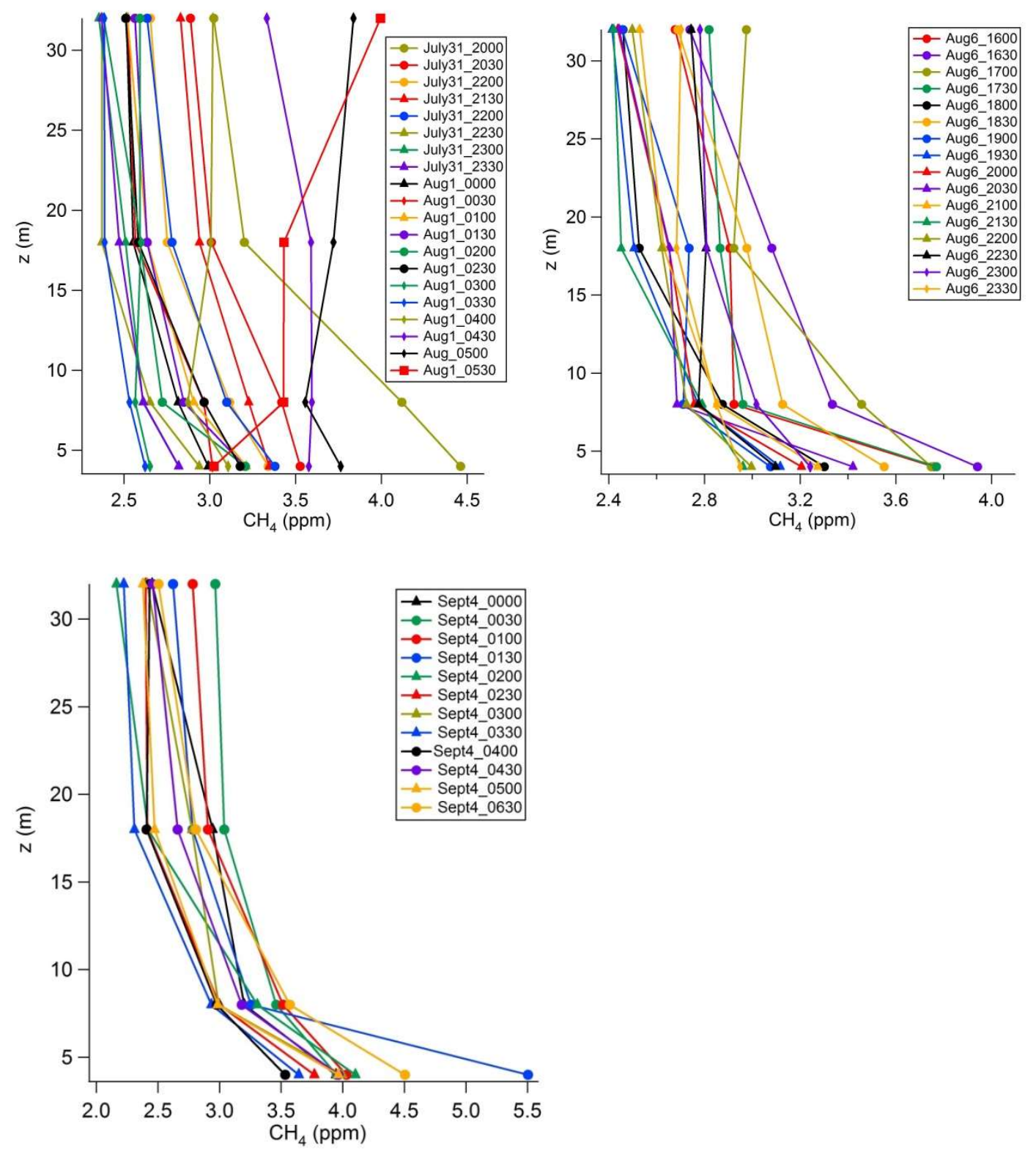

Figure 5 Examples of observed $\mathrm{CH}_{4}$ mole fraction vertical profiles, when the profiles are close to logarithmic. 


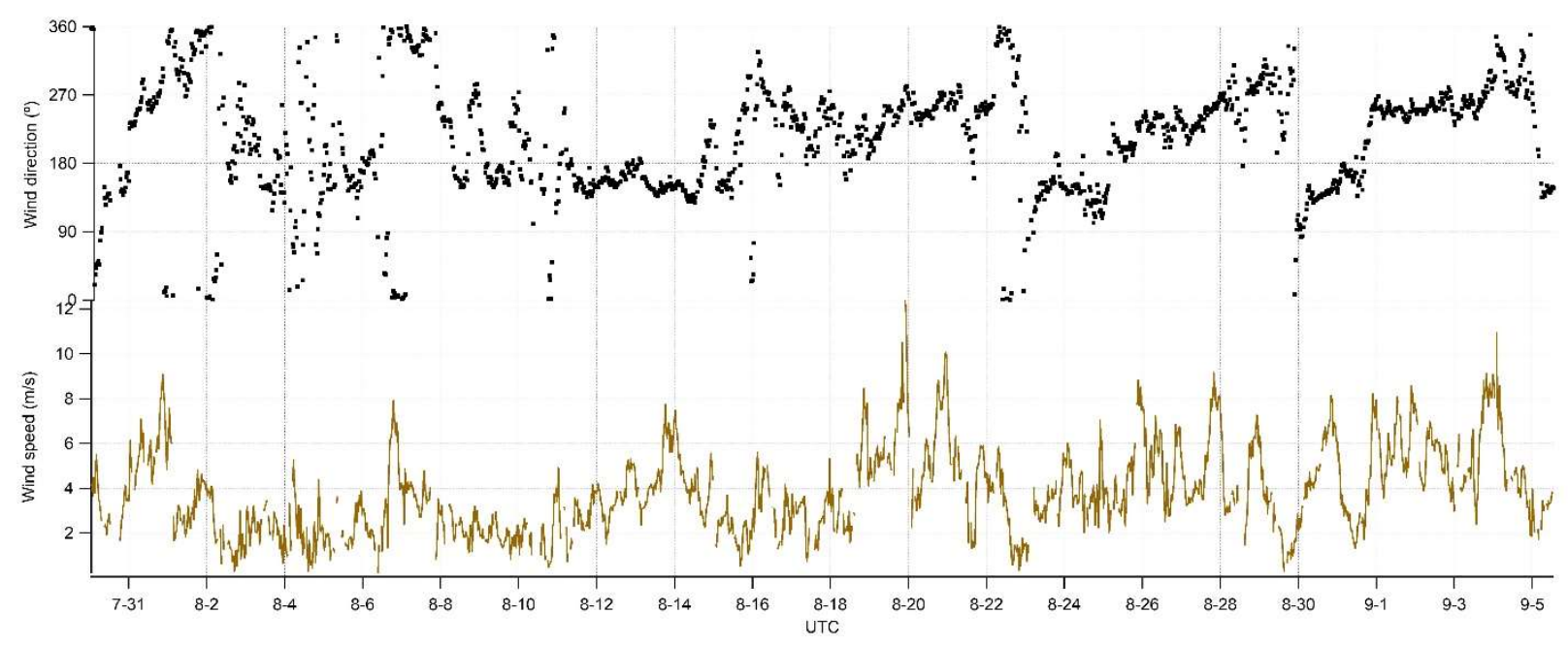

Figure S 6 Time series of wind direction and wind speed measured at $18 \mathrm{~m}$ over the entire project.

To compare to the assumption of linear vertical profile of $\mathrm{CH}_{4}$ mole fractions, the calculation of $K_{c}$ for the assumption of logarithmic vertical profile is also listed here. The representative average height of the FTIR top path with a logarithmic vertical profile would be $Z_{\text {top }}=\sqrt{23 \times 1}=4.8 \mathrm{~m}$. Then, $K_{c}$ for gradient flux calculated from the top-to-bottom path gradient is adjusted logarithmically based on the $K_{c_{-2,4}}$ calculated from point measurements at $8 \mathrm{~m}$ and $32 \mathrm{~m}$ on the tower:

$F_{\text {gradient }_{F T I R}}=-K_{C_{-} F T I R_{-} l o g} \times \frac{\partial c}{\partial z}=\frac{-K_{C_{F T I R \_l o g}} * \partial c}{z * \ln \left(\frac{z_{2}}{z_{1}}\right)}=-\frac{K_{m F T I R \_l o g}}{K_{m 8,32 m}} \times K_{C_{8,32 m}} \times \frac{\partial c}{\sqrt{4.79 \times 1} \times \ln \left(\frac{4.79}{1}\right)}=-0.291 \times$

$\frac{K_{m F T I R \_l o g}}{K_{m 8,32 m}} \times K_{c_{8,32 m}} \times \partial c(\mathrm{~S} .2)$,

where $\mathrm{z}$ is the height for which flux is calculated (Thompson and Pinker, 1981).

$\frac{K_{m F T I R} \log }{K_{m 8,32 m}}$ is a function of stability (z/L) and is calculated with eq. (5) and (6) in the main text. The gradient flux of $\mathrm{CH}_{4}$ with logarithmic vertical profile is calculated with eq. (S2) and the area-weighted average flux from the pond sectors is $4.1 \mathrm{gm}^{-2} \mathrm{~d}^{-1}$, which is $19 \%$ greater than the gradient flux calculated with linear vertical profile.

Beside top-bottom paths of $\mathrm{CH}_{4}$ mole fractions gradient, middle-bottom paths of gradient can also be used to calculate $\mathrm{CH}_{4}$ gradient fluxes. The results are summarised in the first row of Table $\mathrm{S} 1$ to compare to gradient fluxes with top-bottom paths $\mathrm{CH}_{4}$ gradients. The area-weighted averaged fluxes with middle-bottom paths is $29 \%$ lower than the area-weighted averaged fluxes with top-bottom paths (Table S1). 


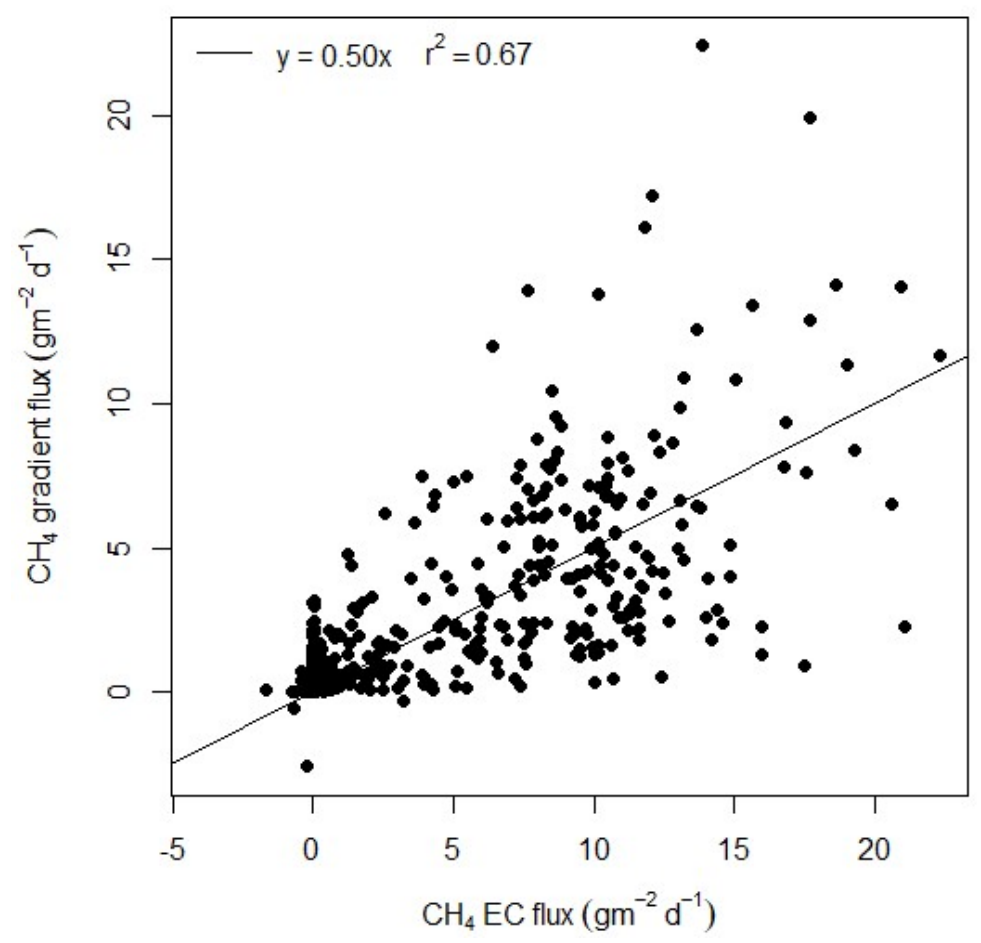

Figure S $7 \mathrm{CH}_{4}$ gradient flux from OP- FTIR compared with EC flux.

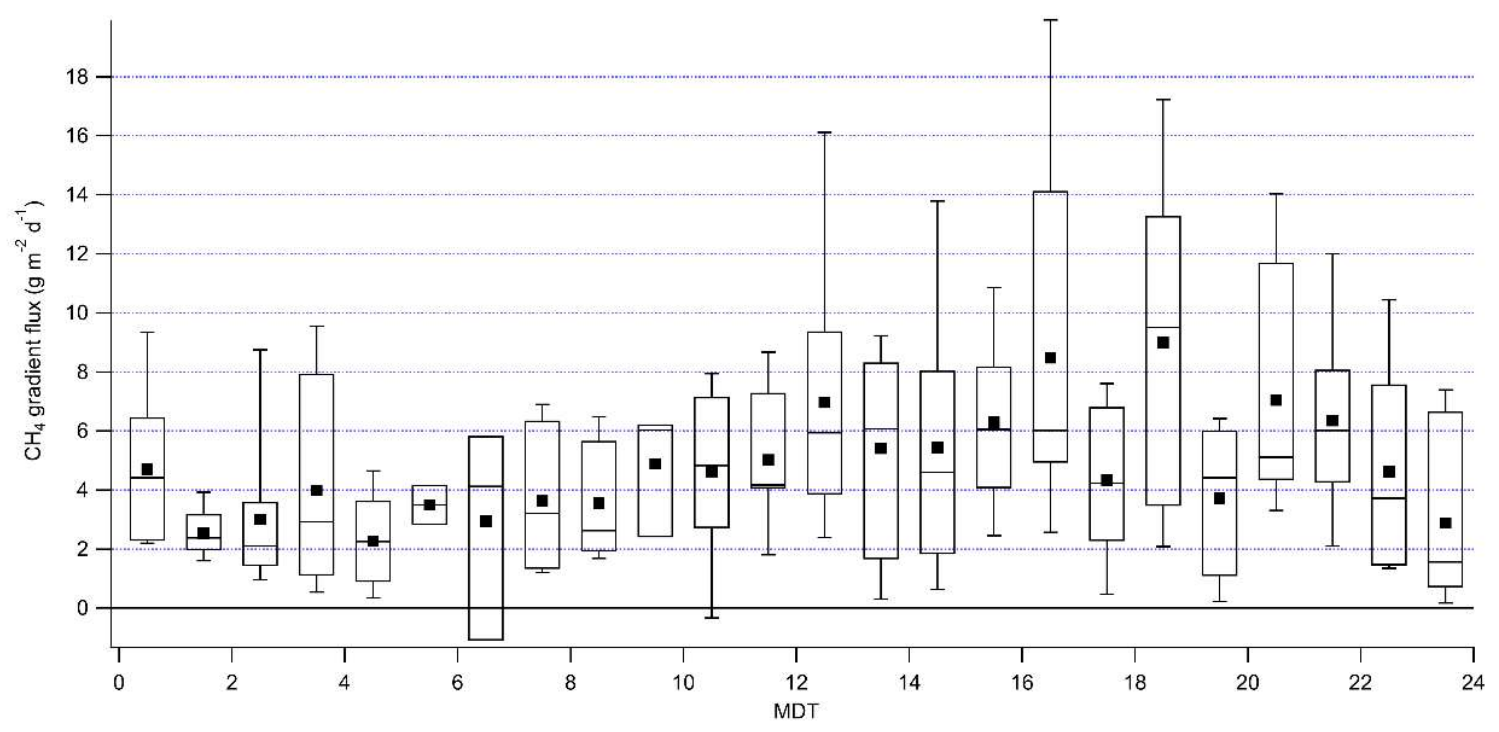

Figure $\mathrm{S} 8$ Diurnal variation of $\mathrm{CH}_{4}$ gradient flux from FTIR, when the wind came from the pond direction. MDT = mountain daylight savings time. Lower and upper bounds of the box plot are the $25^{\text {th }}$ and $75^{\text {th }}$ percentile; the line in the box marks the median and the black square labels the mean; the whiskers label the $10^{\text {th }}$ and $90^{\text {th }}$ percentile. 


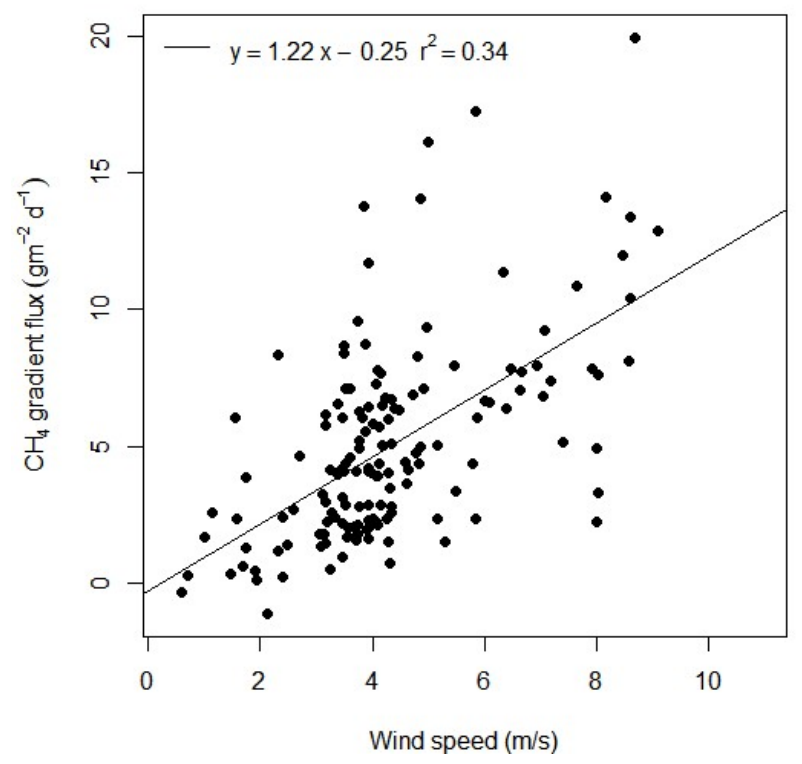

Figure $\mathrm{S} 9 \mathrm{CH}_{4}$ gradient flux when the wind was from the pond.

S1.3 IDM flux of CH4 with two approaches of determining background mole fraction input IDM fluxes of $\mathrm{CH}_{4}$ with input from FTIR. Fluxes comparison with background mole fraction using ECCC measurement at south, and AEP measurements at north: 


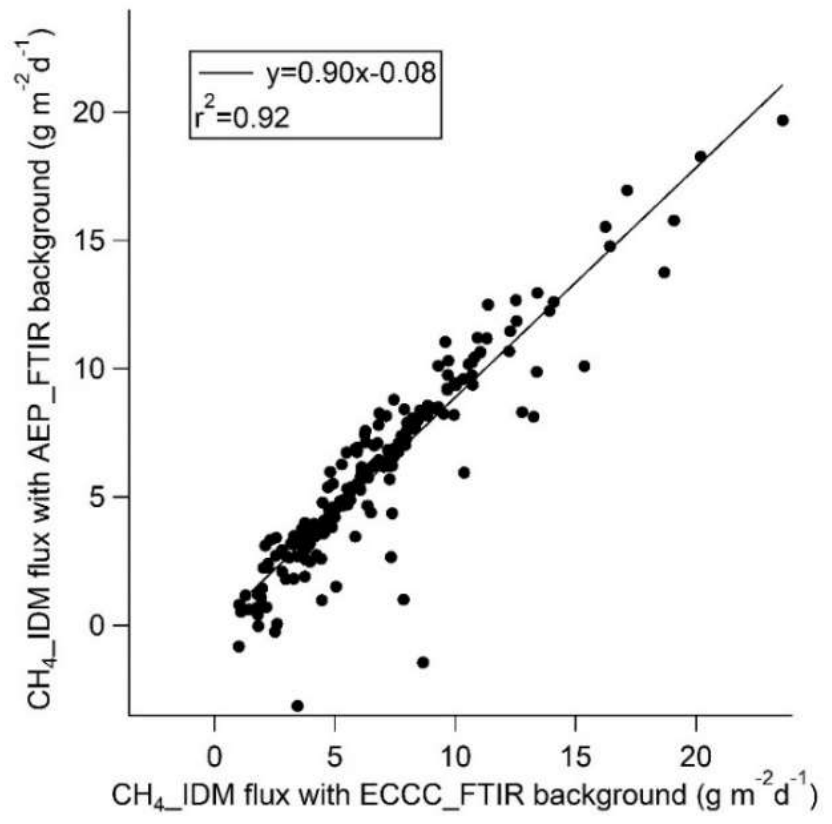

Figure $\mathrm{S} 10$ comparison of $\mathrm{CH}_{4}$ IDM fluxes with input background mole fraction from the south and north measurements.

The half-hour IDM fluxes with these two approaches agree well (slope $=0.9, \mathrm{r}^{2}=0.92$ ). The sector-area-weightaveraged IDM fluxes with two approaches are also within $20 \%$ difference. The interquartile ranges overlap (Table S1). 
S2. $\mathrm{NH}_{3}$
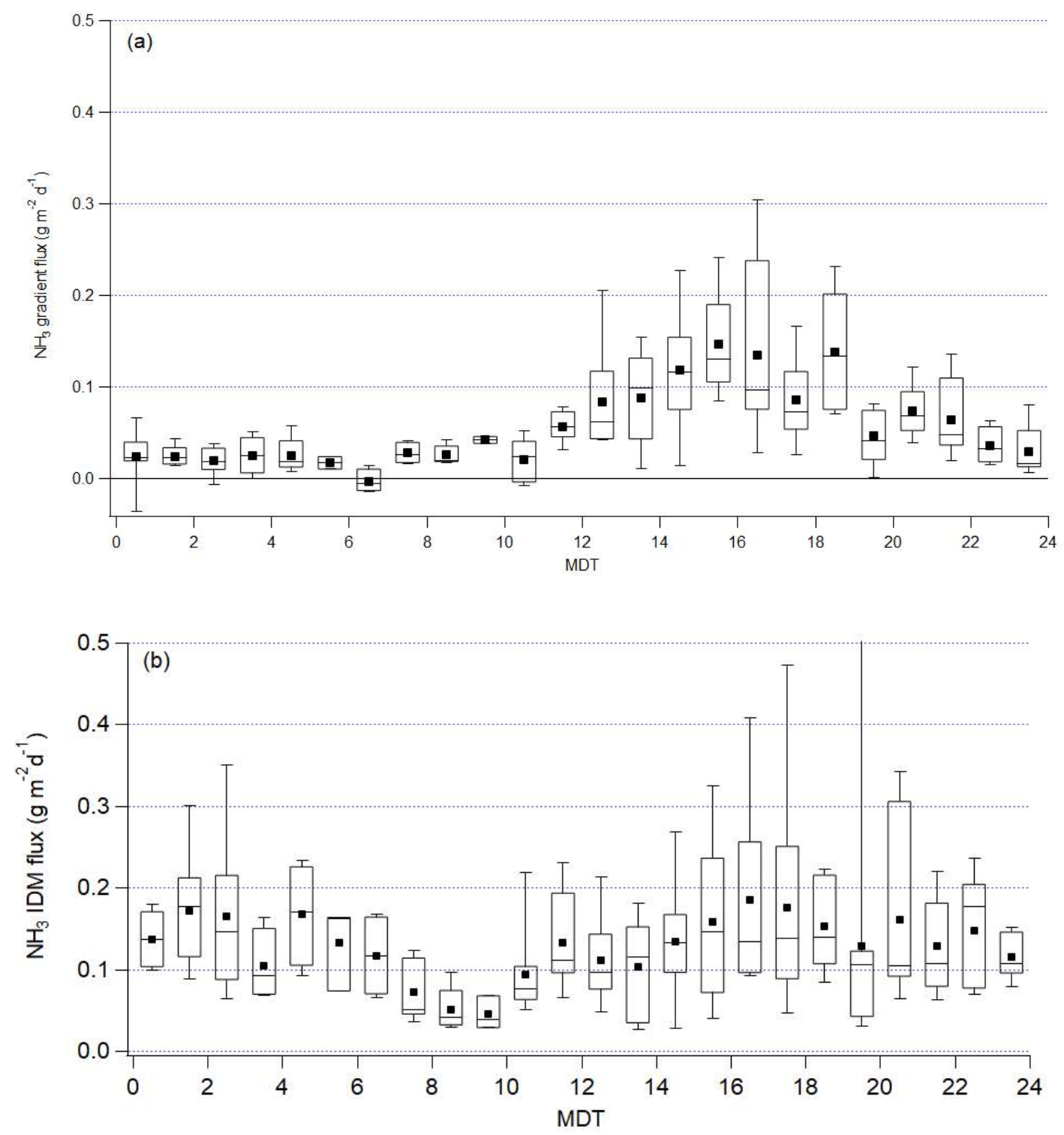

Figure S 11 Diurnal variations of $\mathrm{NH}_{3}$ gradient flux derived from top-bottom paths (a) and IDM flux (b) when the wind was from the pond direction. MDT = mountain daylight savings time. Lower and upper bounds of the box plot are the $25^{\text {th }}$ and $75^{\text {th }}$ percentile; the line in the box marks the median and the black square labels the mean; the whiskers label the $10^{\text {th }}$ and $90^{\text {th }}$ percentile. 

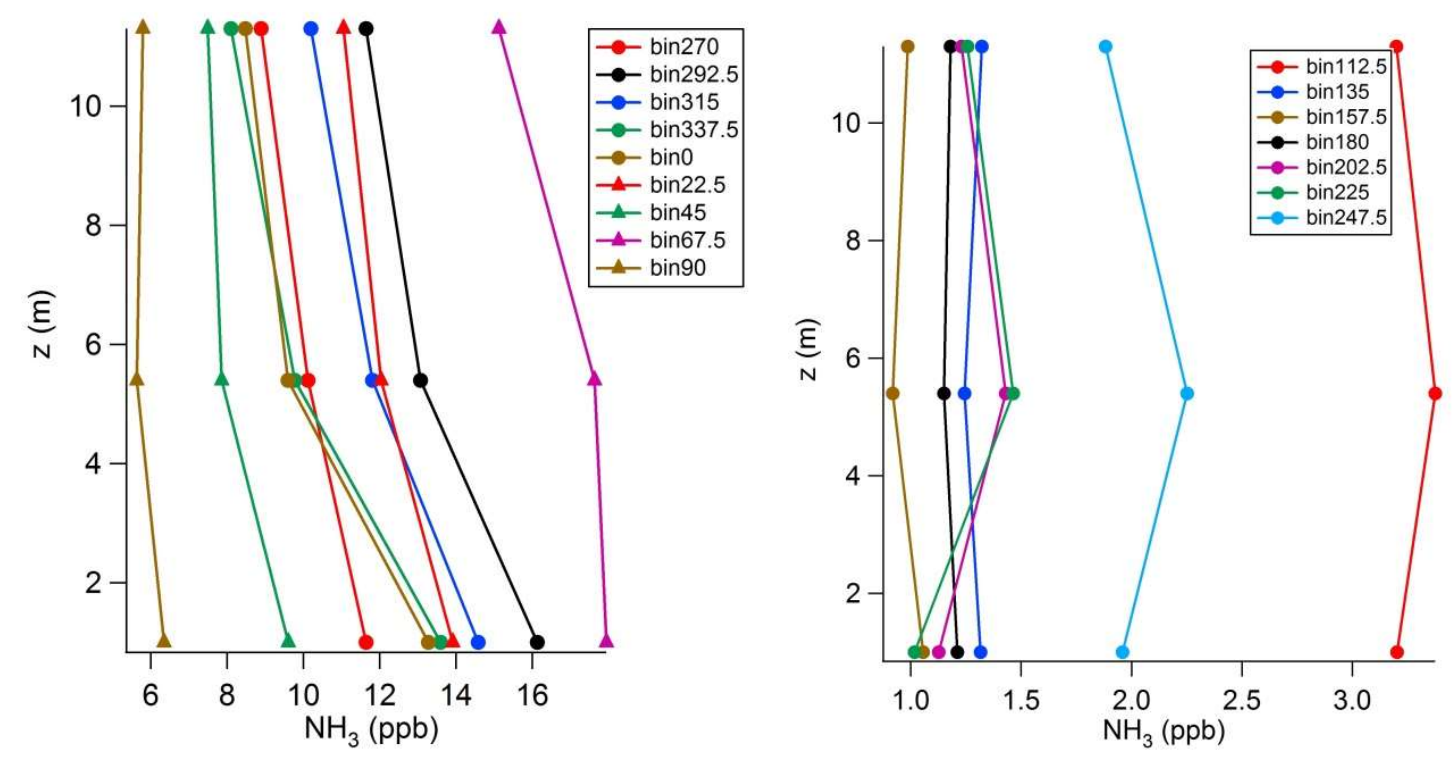

Figure $\mathrm{S} 12 \mathrm{NH}_{3}$ mole fraction vertical profiles after averaging in 16 wind direction sectors. The height $\mathrm{z}$ for the three paths are the height of the middle point of each path.

\section{S3. Total alkane}

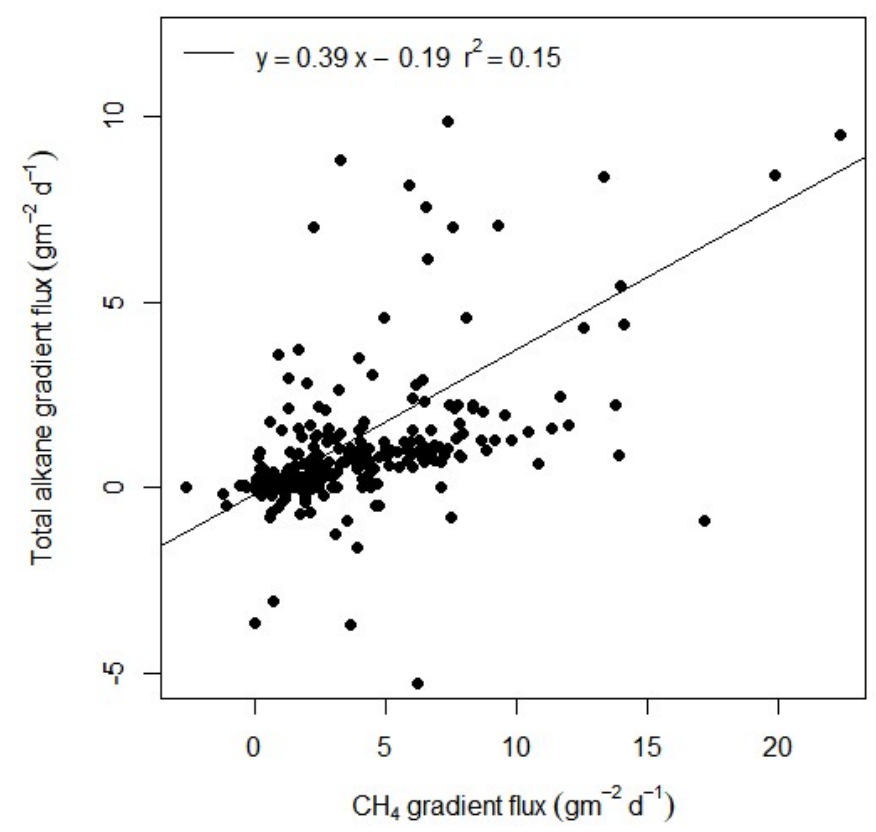

Figure S 13 Total alkane gradient flux compared to $\mathrm{CH}_{4}$ gradient flux, both derived from OP-FTIR top and bottom paths. 


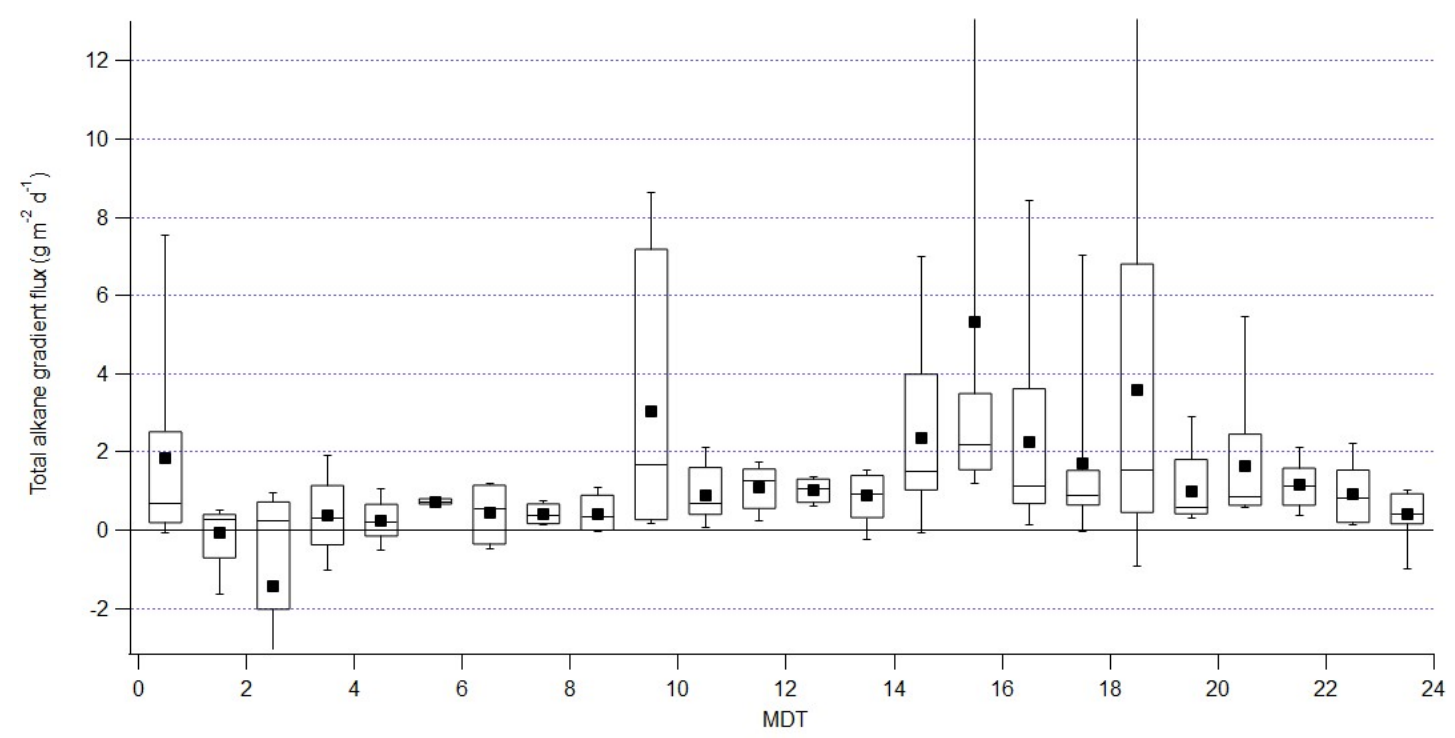

Figure S 14 Diurnal variation of total alkane gradient flux when the wind was from the pond direction. MDT = mountain daylight savings time. Lower and upper bounds of the box plot are the $25^{\text {th }}$ and $75^{\text {th }}$ percentile; the line in the box marks the median and the black square labels the mean; the whiskers label the $10^{\text {th }}$ and $90^{\text {th }}$ percentile.
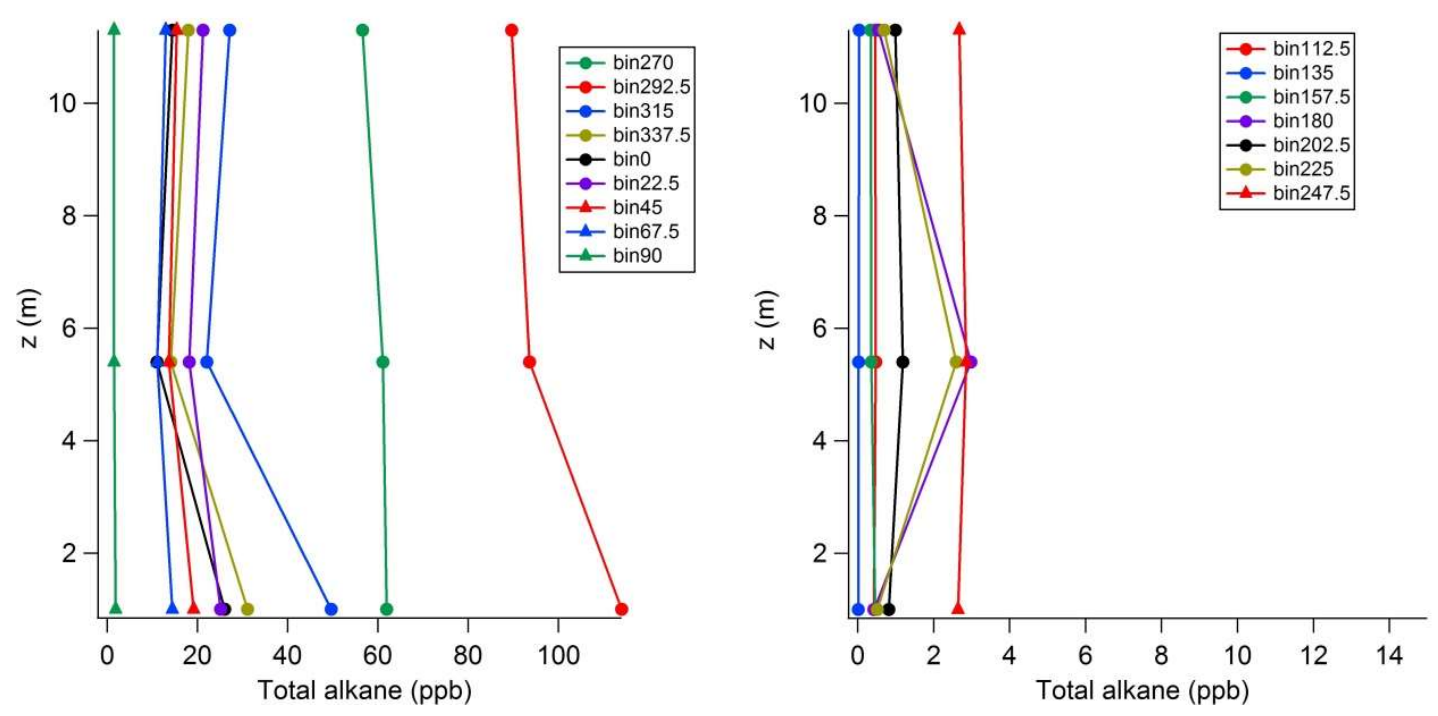

Figure $S 15$ Total alkane mole fraction vertical profiles after averaging in 16 wind direction sectors. The height $\mathrm{z}$ for the three paths are the height of the middle point of each path. 


\section{S4. Methanol $\left(\mathrm{CH}_{3} \mathrm{OH}\right)$}

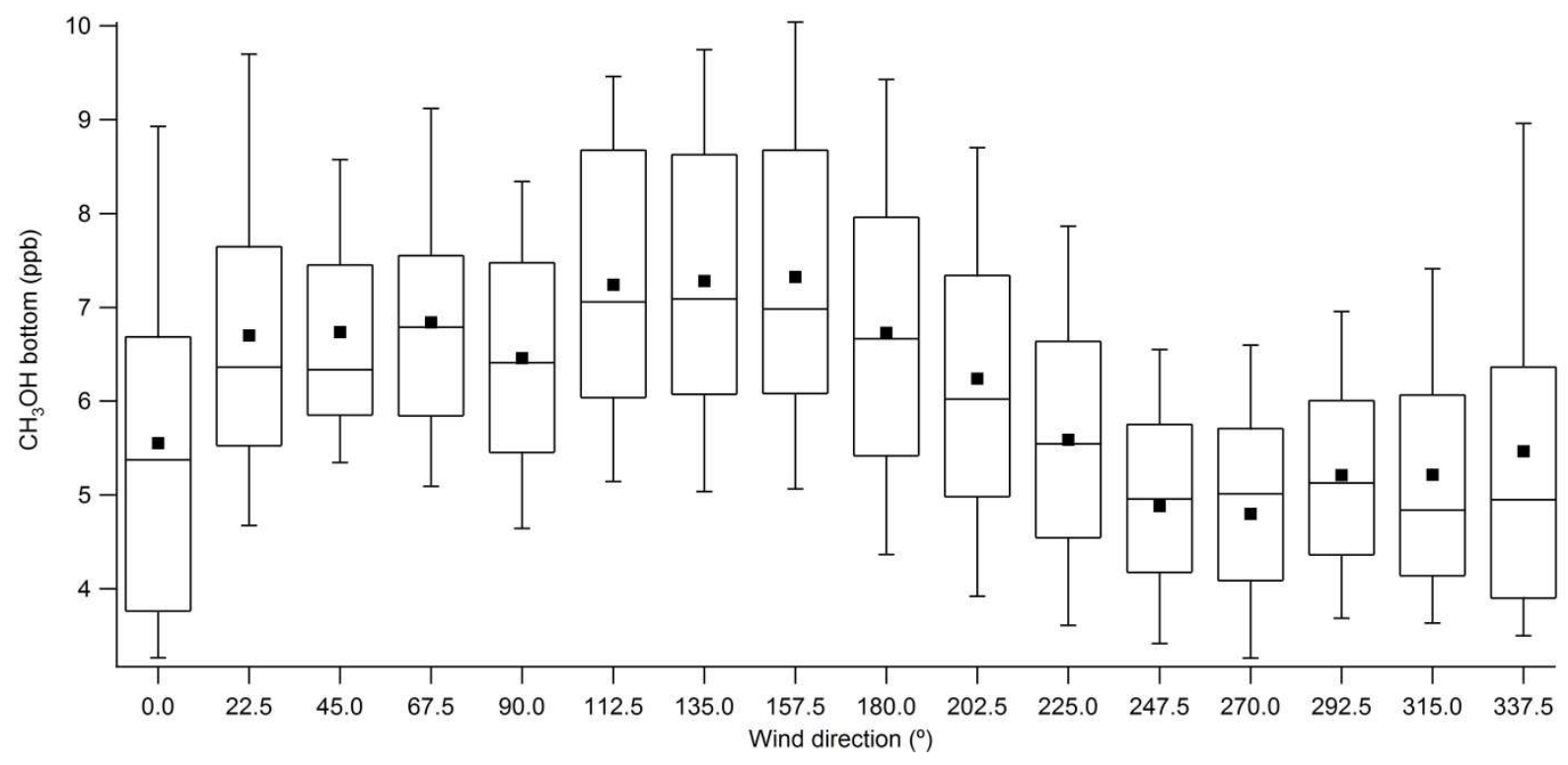

Figure $\mathrm{S} 16 \mathrm{CH}_{3} \mathrm{OH}$ mole fraction retrieved from the FTIR bottom path, binned in $22.5^{\circ}$ sectors. Lower and upper bounds of the box plot are the $25^{\text {th }}$ and $75^{\text {th }}$ percentile; the line in the box marks the median and the black square labels the mean; the whiskers label the $10^{\text {th }}$ and $90^{\text {th }}$ percentile.

\section{S5. Flux results with the slant path approach from Flesch et al. (2016)}

As briefly discussed in the introduction of the main text, Flesch et al., (2016) deployed OP-FTIR measurement with "slant path" configuration, and derived emission rates of $\mathrm{N}_{2} \mathrm{O}$ and $\mathrm{NH}_{3}$ by flux-gradient method. To compare the methods we used to calculate gradient fluxes with their approach, we also performed similar calculation. The derived $\mathrm{u} *$ and $\mathrm{L}$ directly from sonic anemometer measurement at $8 \mathrm{~m}$ on the tower, mole fraction difference between top and bottom paths of FTIR, and calculated $S_{c}$ were plugged in equation (9) in Flesch et al., (2016). In this study, calculated $S_{c}$ is allowed to vary with dynamic stability (You et al. (2021) Fig. 3), while in Flesch et al. (2016) $S_{c}$ was a constant 0.64 . The time series of half-hour gradient fluxes of $\mathrm{CH}_{4}, \mathrm{NH}_{3}$ and total alkane were calculated. Areaweight-averaged fluxes were calculated and summarized in Table S1. Compared to gradient flux results with our approach modified Bowen ratio, $\mathrm{CH}_{4}, \mathrm{NH}_{3}$ and total alkane fluxes with the slant path flux-gradient method are $24 \%$, $25 \%$, and $30 \%$ smaller. 
Tables

Table S1 Summary of $\mathrm{CH}_{4}$ IDM fluxes with two background approaches, and gradient fluxes with approach from Flesch et al. (2016).

\begin{tabular}{|l|c|c|c|c|}
\hline \multicolumn{1}{|c|}{$\left(\mathrm{g} \mathrm{m}^{-2} \mathrm{~d}^{-1}\right)$} & Q_25\% & median & Q_75\% & mean $^{\mathrm{a}}$ \\
\hline $\begin{array}{l}\mathrm{CH}_{4} \text { _gradient flux with middle-bottom } \\
\text { paths }\end{array}$ & 1.5 & 2.6 & 4.1 & $3.0 \pm 1.3$ \\
\hline $\mathrm{CH}_{4}$ IDM flux_with ECCC background & 3.6 & 5.2 & 6.6 & $5.4 \pm 0.4$ \\
\hline $\mathrm{CH}_{4}$ _IDM flux_with AEP background & 2.9 & 4.4 & 5.6 & $4.3 \pm 0.6$ \\
\hline $\begin{array}{l}\mathrm{CH}_{4} \text { gradient flux with approach from } \\
\text { Flesch et al. (2016) }\end{array}$ & 1.5 & 2.9 & 4.6 & $3.3 \pm 1.3$ \\
\hline $\begin{array}{l}\text { NH} \text { gradient flux with approach from } \\
\text { Flesch et al. (2016) }\end{array}$ & 0.01 & 0.03 & 0.06 & $0.04 \pm 0.01$ \\
\hline $\begin{array}{l}\text { Total alkane gradient flux with approach } \\
\text { from Flesch et al. (2016) }\end{array}$ & 0.16 & 0.50 & 1.08 & $0.74 \pm 0.15$ \\
\hline
\end{tabular}

${ }^{a}$ Errors with the mean fluxes are calculated with an integrative approach: the average of observed standard deviations of fluxes from five periods when the fluxes displayed high stationarity.

\section{Reference}

Kljun, N., Calanca, P., Rotach, M. W., and Schmid, H. P.: A simple two-dimensional parameterisation for Flux Footprint Prediction (FFP), Geosci. Model Dev., 8, 3695-3713, http://doi.org/10.5194/gmd-8-3695-2015, 2015.

Thompson, O. E., and Pinker, R. T.: An error analysis of the Thornthwaite-Holzman equations for estimating sensible and latent heat fluxes over crop and forest canopies, J. Appl. Meteorol., 20, 250-254, 1981. 